Research Paper

\title{
Graiting Helps Improve Photosynthesis and Carbohydrate Metabolism in Leaves of Muskmelon
}

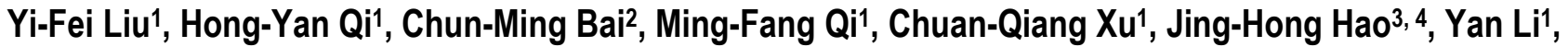 \\ Tian-Lai Li ${ }^{1} \otimes$
}

1. Shenyang Agricultural University (SYAU), Shenyang 110866, China

2. Liaoning Academy of Agricultural Sciences (LAAS), Shenyang 110161, China

3. Institute of Vegetables and Flowers, The Chinese Academy of Agricultural Sciences (CAAS), Beijing 100081, China

4. Beijing University of Agriculture, Beijing 102206, China

\begin{abstract}
$\triangle$ Corresponding author: Tian-Lai Li, Vice-President of Shenyang Agricultural University, Chief Director of Key Laboratory of the Ministry of Education for Protected Horticulture, Shenyang Agricultural University, Shenyang 110866, China; Tel:+86-24-88487166; fax:+86-24-88487166; E-mail: tianlaili@126.com
\end{abstract}

(c) Ivyspring International Publisher. This is an open-access article distributed under the terms of the Creative Commons License (http://creativecommons.org/ licenses/by-nc-nd/3.0/). Reproduction is permitted for personal, noncommercial use, provided that the article is in whole, unmodified, and properly cited.

Received: 2011.03.22; Accepted: 2011.10.06; Published: 2011.10.19

\begin{abstract}
The most important quality for muskmelon (Cucumis melo L.) is their sweetness which is closely related to the soluble sugars content. Leaves are the main photosynthetic organs in plants and thus the source of sugar accumulation in fruits since sugars are translocated from leaves to fruits. The effects of grafting muskmelon on two different inter-specific (Cucurbita maxima $\times C$. moschata) rootstocks was investigated with respect to photosynthesis and carbohydrate metabolism. Grafting Zhongmil muskmelon on RibenStrong (GR) or Shengzhen I (GS) rootstocks increased chlorophyll $a$, chlorophyll $b$ and chlorophyll $a+b$ content and the leaf area in middle and late developmental stages of the plant compared to the ungrafted Zhongmil check (CK). Grafting enhanced the net photosynthesis rate, the stomatal conductance, concentration of intercellular $\mathrm{CO}_{2}$ and transpiration rate. Grafting influenced carbohydrates contents by changing carbohydrate metabolic enzymes activities which was observed as an increase in acid invertase and neutral invertase activity in the functional leaves during the early and middle developmental stages compared to CK. Grafting improved sucrose phosphate synthase and stachyose synthase activities in middle and late developmental stages, thus translocation of sugars (such as sucrose, raffinose and stachyose) in GR and GS leaves were significantly enhanced. However, compared with CK, translocation of more sugars in grafted plants did not exert feedback inhibition on photosynthesis. Our results indicate that grafting muskmelon on inter-specific rootstocks enhances photosynthesis and translocation of sugars in muskmelon leaves.
\end{abstract}

Key words: Chlorophyll content; Photosynthesis; Raffinose family oligosaccharides (RFOs); Carbohydrate metabolism; Grafting; Muskmelon

\section{Introduction}

Muskmelon is one of the top ten fruit crops grown widely in the world for their delicious sweetness, high nutrient quality and flavor $[1,2]$. However, owing to large market requirements for off season cucurbits and limited availability of arable land, muskmelons are continuously cultivated under less than ideal conditions worldwide including environ- ments that are too wet, cold and dry, or in cool low-light winter greenhouses such as the conditions prevalent in northern regions of China [3, 4]. Successive cropping can also increase salinity, the incidence of cucurbit pests, and serious devastating soil-borne diseases such as muskmelon wilt (Fusarium oxysporum f. melonis) and root-knot nematodes (Meloidogyne 
spp) that can result in severe crop loss [5-7]. Chemical control can be expensive and is not always effective. Furthermore chemical control could also harm the environment [4].

To overcome some of these problems described above, grafting muskmelon on a suitable rootstock is widely being adapted globally, to manage soil-borne diseases of muskmelon and the continuous cultivation barriers [8-10]. Grafted vegetables have been cultivated in eastern Asia for decades [5], but their adoption all over the world has only begun since the banning of the fumigant methyl bromide in 2005 by the Montreal Protocol [11]. Numerous researchers have confirmed that grafting on rootstocks belonging to a different genera can alter muskmelon fruit quality in various ways [5, 12-14]. For instance, total carbohydrate contents in grafted muskmelon and watermelon were reduced significantly compared with self-rooted plants $[4,15,16]$ thus, influencing muskmelon fruit flavor and other quality such as sweetness $[17,18]$. It is well known that leaves, the main photosynthetic organ in plants, are the source of carbohydrates accumulation in fruits and supply carbon for synthesis of sugars and carbohydrate metabolism. Leaf photosynthesis is pivotal for fruit growth and quality. The change in chlorophyll content, photosynthetic rates and carbohydrate partitioning in source leaves can alter photoassimilates export rates, which are directly related to carbohydrate accumulation in fruits that act as the sink [19-21]. The plants in Cucurbitaceae family transport stachyose, and some partial sucrose and raffinose in phloem tissue [22-25], thus sucrose and stachyose metabolism in muskmelon leaves play a central role in carbohydrate synthesis. Photosynthesis and sucrose or stachyose metabolic enzymes activities concern carbohydrate synthesis capacity in leaves, while carbohydrate accumulation in leaves will be determined by the carbohydrate synthesis, loading and transportation levels [26]. Meanwhile carbohydrate accumulation levels in leaves will feedback regulate photosynthesis and the activities of carbohydrate metabolism related enzymes [27]. The objectives of this study were to evaluate the effects of grafting on photosynthesis and carbohydrate metabolism in muskmelon leaves grafted on inter-specific hybrid rootstocks.

\section{Materials and Methods}

\section{Plant materials and sampling}

Seeds of 'Zhongmi1' a popular muskmelon (Cucumis melo L.), cultivar (commercial maturity 40 days after anthesis [DAA] roughly) were kindly pro- vided by Mr. Huaisong Wang (Chinese Academy of Agricultural Sciences, CAAS) and used as scion in all experiments. Rootstocks (Cucurbita maxima $\times$ C. moschata 'RibenStrong' and 'Shengzhen1') were grown in a sand/soil/peat (1:1:1 by volume) mixture. For grafting, rootstock seeds were sown for 7 days to produce seedlings with approximately the same size of hypocotyls as that of muskmelon. Tongue approach grafting was carried out at the two-leaf stage of the muskmelon seedlings. Ungrafted plants (self-rooted control), Zhongmi1/RibenStrong, Zhongmi1/Shengzhen1 graft combinations were named as CK, GR and GS respectively. Approximately 20 days after grafting, the seedlings were transplanted into plastic pots (with upper diameter, base diameter and height of 30, 24 and $25.5 \mathrm{~cm}$, respectively) with NPK (2:1:2) fertilizer in a Liaoshen-2 solar greenhouse (Patent right possessed by High-efficiency Industrialized Agricultural Engineering Technology Research Center of Liaoning Province). All plants were managed as using standard production practices followed in northern regions of China [4]. To identify fruit of known age, freshly opened female flowers were tagged on the day of hand-pollination and one fruit per plant was allowed to develop at 12th node. Leaves from fruit-carrying nodes in each treatments were collected on $8,16,24$, 32, 40 (fruit maturity) and 48 DAA (delayed fruit harvest period), between 10:00 am and 12:00 am, frozen in liquid nitrogen and stored at $-80^{\circ} \mathrm{C}$ for carbohydrates and enzymatic activity assessment. All experiments were repeated three times with three replicates for each analysis.

\section{Photosynthetic measurements}

Net photosynthetic rates, stomatal conductance, concentration of intercellular $\mathrm{CO}_{2}$ and transpiration rate of leaves from fruit-carrying nodes in each treatment were measured on $8,16,24,32,40$ and 48 DAA with a portable photosynthesis system (Li-Cor 6400; Li-Cor Inc., Nebraska, USA), between 9:00 am and 11:00 am with constant irradiation (600 $\mu \mathrm{mol}$ photons $\left.\mathrm{m}^{-2} \mathrm{~s}^{-1}, \mathrm{PAR}\right)$. Each leaf was equilibrated in the leaf chamber for at least $1 \mathrm{~min}$ before a measurement was taken. And leaf area was measured with a LI-3100 A (Li-Cor Inc.). Three plants were examined and the means were calculated across replicates.

After collecting photosynthetic measurements, $0.25 \mathrm{~g}$ of fresh leaves were placed in a $100 \mathrm{ml}$ test tube for the determination of the chlorophyll content, then 10-15 ml pure methanol was added, and homogenized with a polytron. The homogenate was then filtered and made up to $100 \mathrm{ml}$ with pure methanol. The chlorophyll concentration in the supernatant was 
spectrophotometrically determined by measuring the absorbances at 652.0 and $665.2 \mathrm{~nm}$ for chlorophyll $a$ and chlorophyll $b$, respectively, and calculated according to Porra's method. [28]. All experiments were repeated three times with three replicates.

\section{Soluble carbohydrate analysis}

Soluble carbohydrates in leaves were extracted with $80 \%$ (v/v) ethanol ( $15 \mathrm{ml}$ per $6 \mathrm{~g}$ sample $\mathrm{FW})$ at $80{ }^{\circ} \mathrm{C}$ for $1 \mathrm{~h}$. Ethanol extracts were collected and the pellets re-extracted twice using the same method. The extracts were subsequently cleaned via a Waters Sep-Pak column $\left(\mathrm{C}_{18}\right.$, Accell Plus QMA and Accell Plus CM), combined and dried in a centrifugal evaporator (MAXI dry Lyo). The dry extracts were dissolved in $500 \mu \mathrm{L}$ ultra-pure water, filtered through an acetate filter ( $0.22 \mu \mathrm{m}$ pore size, Nalgene), and $20 \mu \mathrm{l}$ samples were analyzed for sugar content by HPLC using a Waters 600 controller fitted with a Luna 5U $\mathrm{NH}_{2}$ 100R column (Phenomenex Separation Products, USA), Waters 2410 Refractive Index Detector, Waters In-Line Degasser AF, and Waters 600 pump as previously described [20]. The separations were performed at $35{ }^{\circ} \mathrm{C}$ and eluted with 75/25 (v/v) acetonitrile $/ \mathrm{H}_{2} \mathrm{O}$ at a flow rate of $1 \mathrm{ml} \mathrm{min}{ }^{-1}$. Fructose (Product No. 31140), glucose (Product No. G5400), sucrose (Product No. 84099), raffinose (Product No. R0250), galactinol (Product No. 79544) and stachyose (Product No. S4001) were determined by co-elution with standards (SIGMA-ALDRICH Co., 3050 Spruce Street, St. Louis, MO63103 USA). According to retention time to distinguish different kinds of sugars, fructose, glucose, sucrose, raffinose, galactinol and stachyose were detected at $4.858 \mathrm{~min}, 5.315 \mathrm{~min}, 6.710$ min, $11.664 \mathrm{~min}, 12.885$ and $21.923 \mathrm{~min}$ in Auto-Scaled Chromatogram of HPLC, respectively. Waters Millennium software was used for controlling and data processing.

\section{Enzyme extractions and activity assays}

Leaf samples were finely ground in liquid nitrogen using a chilled mortar and pestle. Approximately $1 \mathrm{~g}$ of the ground tissue was suspended in $1 \mathrm{ml}$ of ice-cold extraction buffer containing $50 \mathrm{mM}$ HEPES-NaOH (pH 7.5), $10 \mathrm{mM}$ ascorbic acid, $2.5 \mathrm{mM}$ dithiothreitol (DTT), $10 \mathrm{mM} \mathrm{MgCl} 2,10 \%$ (v/v) ethylene glycol (pH 7.5), and $1 \mathrm{mM}$ EDTA. The extracts were filtered through cheesecloth, and centrifuged at $26,000 \mathrm{~g}$ (unit of speed) for $20 \mathrm{~min}$ at $4^{\circ} \mathrm{C}$. The supernatant was desalted by dialyzing for more than $20 \mathrm{~h}$ at $4^{\circ} \mathrm{C}$.

Acid invertase (AI) and neutral invertase (NI) (EC 3.2.1.26) activities were assayed in a final volume of $25 \mathrm{ml}$, containing $0.2 \mathrm{ml}$ of dialyzed enzymatic ex- tract, $0.8 \mathrm{ml}$ of reaction solution contained $100 \mathrm{mM}$ $\mathrm{Na}_{2} \mathrm{HPO}_{4}, 100 \mathrm{mM}$ sodium citrate, $100 \mathrm{mM}$ sucrose, and $\mathrm{pH} 4.8$ or 7.2 for acid invertase and neutral invertase, respectively. The activities were measured by the quantity of reducing sugars released in the assay media with dinitrosalicylic acid. The reducing sugars were revealed by incubation at $100^{\circ} \mathrm{C}$ for $5 \mathrm{~min}$ and read at $520 \mathrm{~nm}$ in a Cary 100UV-VIS spectrophotometer (Varian, USA) [29].

Sucrose synthase (SS) (EC 2.4.1.13) activity was measured by using $0.4 \mathrm{ml}$ reaction mixture contained $50 \mathrm{mM}$ fructose, $0.82 \%$ UDPG, $100 \mathrm{mM}$ Tris, $10 \mathrm{mM}$ $\mathrm{MgCl}_{2}$ adding $0.2 \mathrm{ml}$ enzyme at $37^{\circ} \mathrm{C}$ for $30 \mathrm{~min}$ and bathing for $1 \mathrm{~min}$ at $100^{\circ} \mathrm{C}$, and a volume of $1 \mathrm{ml}$ reaction products adding $0.1 \mathrm{ml} 2 \mathrm{M} \mathrm{NaOH}$ was placed in boiling water bath for $10 \mathrm{~min}$ and cooled in water, then adding $3.5 \mathrm{ml} \mathrm{30 \%} \mathrm{HCl}$ and $1 \mathrm{ml} 0.1 \%$ resorcinol. Blank controls were obtained by adding the distilled water to the reaction medium containing resorcinol. The reducing sugars were revealed by incubation at $80^{\circ} \mathrm{C}$ for $10 \mathrm{~min}$ and read at $480 \mathrm{~nm}$ in a Cary 100UV-VIS spectrophotometer (Varian, USA). Sucrose phosphate synthase (SPS) (EC 2.4.1.14) was assayed by measurement of sucrose produced from fructose 6-phosphate plus UDP-glucose[30].

The alkaline a-galactosidase (AGA) (EC 3.2.1.22) was assayed using p-nitrophenyl-a-galactosidase as substrate. The reaction mixture contained $5 \mathrm{mM}$ p-nitrophenyl-a-galactosidase and $100 \mathrm{mM}$ HEPES buffer ( $\mathrm{pH}$ 7.5) for alkaline form activity. Reaction was started by adding $30 \mu$ l enzyme extract and terminated after $20 \mathrm{~min}$ by adding $1 \mathrm{ml} \mathrm{5 \%}(\mathrm{w} / \mathrm{v}$ ) $\mathrm{Na}_{2} \mathrm{CO}_{3}$. The enzyme activity was expressed as micromoles of nitrophenol formation per minute by reading at $410 \mathrm{~nm}$ in a Cary 100UV-VIS spectrophotometer (Varian, USA) [31].

Stachyose synthase activity were determined as previously described [32] with minor modifications. Dialyzed $100 \mathrm{ul}$ extract was added to $100 \mu \mathrm{l}$ reaction buffer containing $50 \mathrm{mM}$ HEPES-NaOH (pH 7.0), 20 $\mathrm{mM}$ 2-mercaptoethanol, $10 \mathrm{mM}$ galactinol and $40 \mathrm{mM}$ raffinose. Duplicate measurements were made for each extract sample. Controls were similar but with the omission of galactinol. Reaction mixtures were incubated at $25^{\circ} \mathrm{C}$ for $90 \mathrm{~min}$ and the reactions were terminated by the addition of $100 \mu \mathrm{l}$ of $0.1 \mathrm{M} \mathrm{NaOH}$. The mixtures were then heated for $30 \mathrm{~s}$ in boiling water and cooled to $25^{\circ} \mathrm{C}$ for $40 \mathrm{~min}$ in the presence of 2 mM NAD, $0.1 \mathrm{U}$ myo-inositol dehydrogenase, and 50 $\mathrm{mM} \mathrm{Na}_{2} \mathrm{CO}_{3}(\mathrm{pH} 9.5)$ in a total reaction volume of 1.0 $\mathrm{ml}$. Reduction of NAD was measured spectrophotometrically at $340 \mathrm{~nm}$ in a Cary 100UV-VIS spectrophotometer (Varian, USA). 


\section{Statistical Analysis}

SPSS 13.0 and Excel 2007 were used for data analysis and graphing.

\section{Results and Discussions}

One of the most important qualities of fruits is sweetness, which is closely related to the soluble sugar content and therefore carbohydrate metabolism plays a pivotal role in development of muskmelon fruit $[4,18]$. It is well known that fruit development is dependent largely upon the supply of photoassimilates imported into the fruit via the phloem from leaves [33]. Carbohydrate accumulation in leaves is a comprehensive reflection of three respects in carbohydrate synthesis, metabolic transformation, loading and export. The productivity and metabolic capacity of the photoassimilates in leaves will exert a direct influence on the loading and export for the carbohydrate in leaves, critically important to the carbohydrate accumulation in fruits. Photosynthesis and carbohydrate metabolic enzymes activities concern carbohydrate synthesis capacity in leaves, while carbohydrate accumulation in leaves will be determined by the carbohydrate synthesis capacity, loading and transportation level. Meanwhile carbohydrate accumulation levels in leaves will feedback regulate photosynthesis and the activities of carbohydrate metabolism related enzymes [27]. Therefore, the present study on the effects of grafting muskmelon on in-

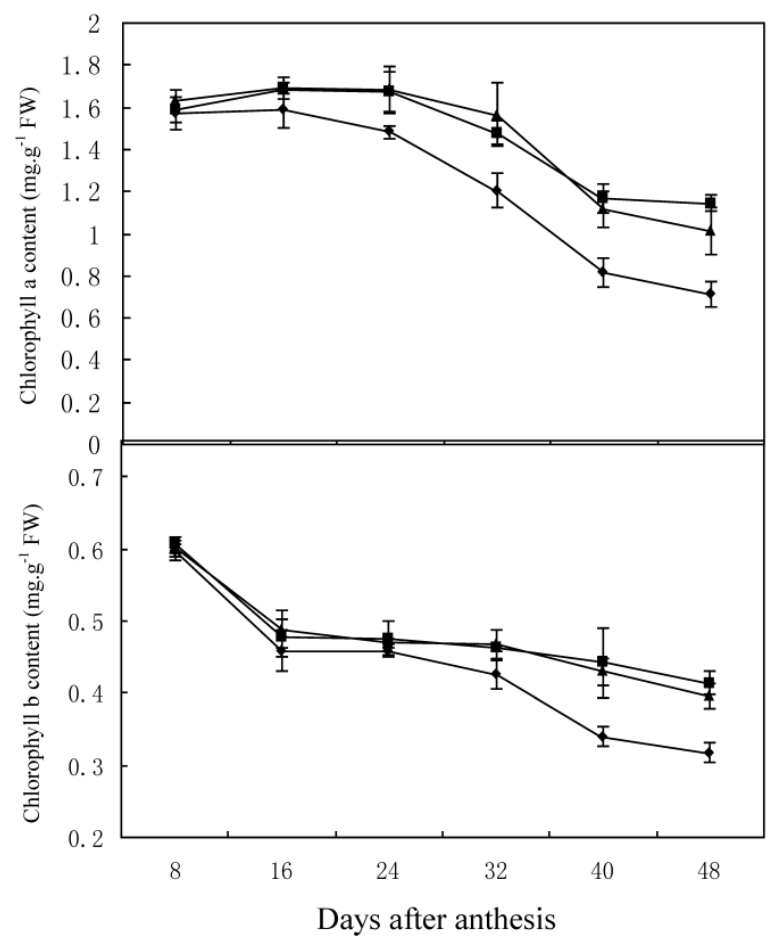

ter-specific hybrid rootstocks on photosynthesis and carbohydrate metabolism in muskmelon leaves is important to help realize high yield and quality.

\section{Effect of grafting on chlorophyll content and photosynthesis level in muskmelon leaves}

Chloroplast, the fundamental substance for photosynthesis, functions by absorbing and transferring light energy. Chlorophyll content, which displays a direct impact on the photosynthetic efficiency in leaves, is a key index in photosynthetic capacity [2]. Compared to most other Suc-translocating plants, photoassimilates in translocation stream of muskmelon is mainly composed of stachyose, along with raffinose and sucrose [34, 35]. As a result sucrose from photosynthesis in leaves will have to be converted into stachyose by a series of enzyme catalysis, and then they can be loaded to phloem for long distance transport to the fruits. Since sucrose is the substrate of stachyose synthesis, the level of photosynthesis also will influence stachyose metabolism in leaves. As this experiment indicates, grafting on inter-specific rootstocks significantly increased chlorophyll $a$ content during 24-48 DAA, chlorophyll $b$ content during 32 to 48 DAA and chlorophyll $a+b$ content during 24-48 DAA (Fig. 1). However, grafting did not change the chlorophyll $a / b$ ratio throughout the developmental stage (Fig. 1). In addition, grafting increased leaf area dramatically during 24-48 DAA (Fig. 1).

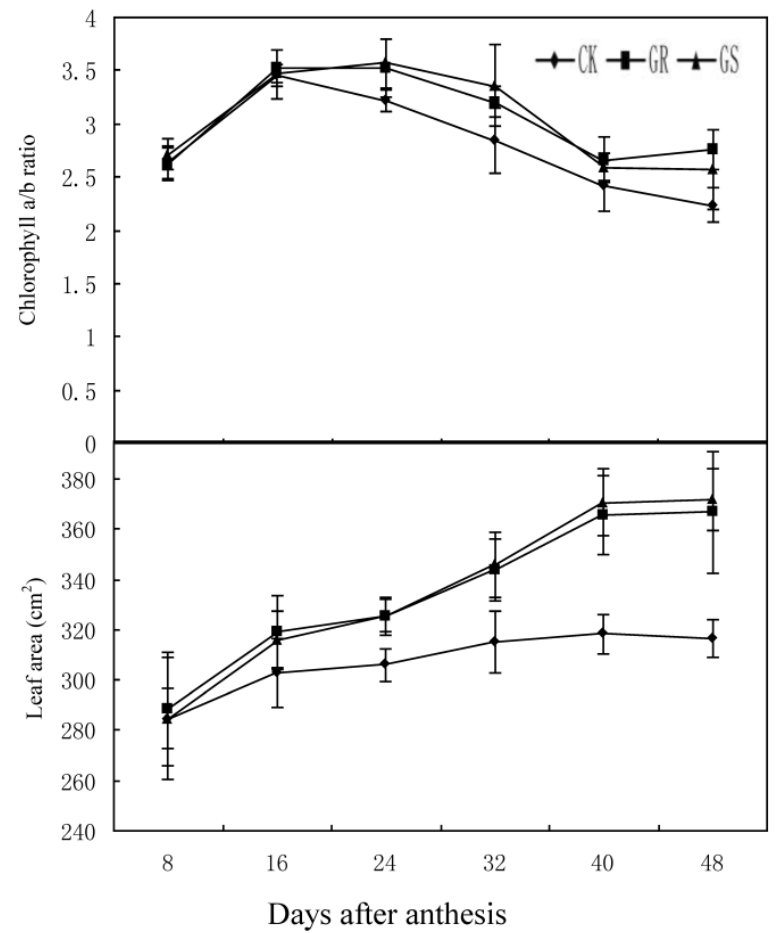

Fig. I Effect of grafting on chlorophyll content, chlorophyll a/b ratio and leaf area in muskmelon leaves. 

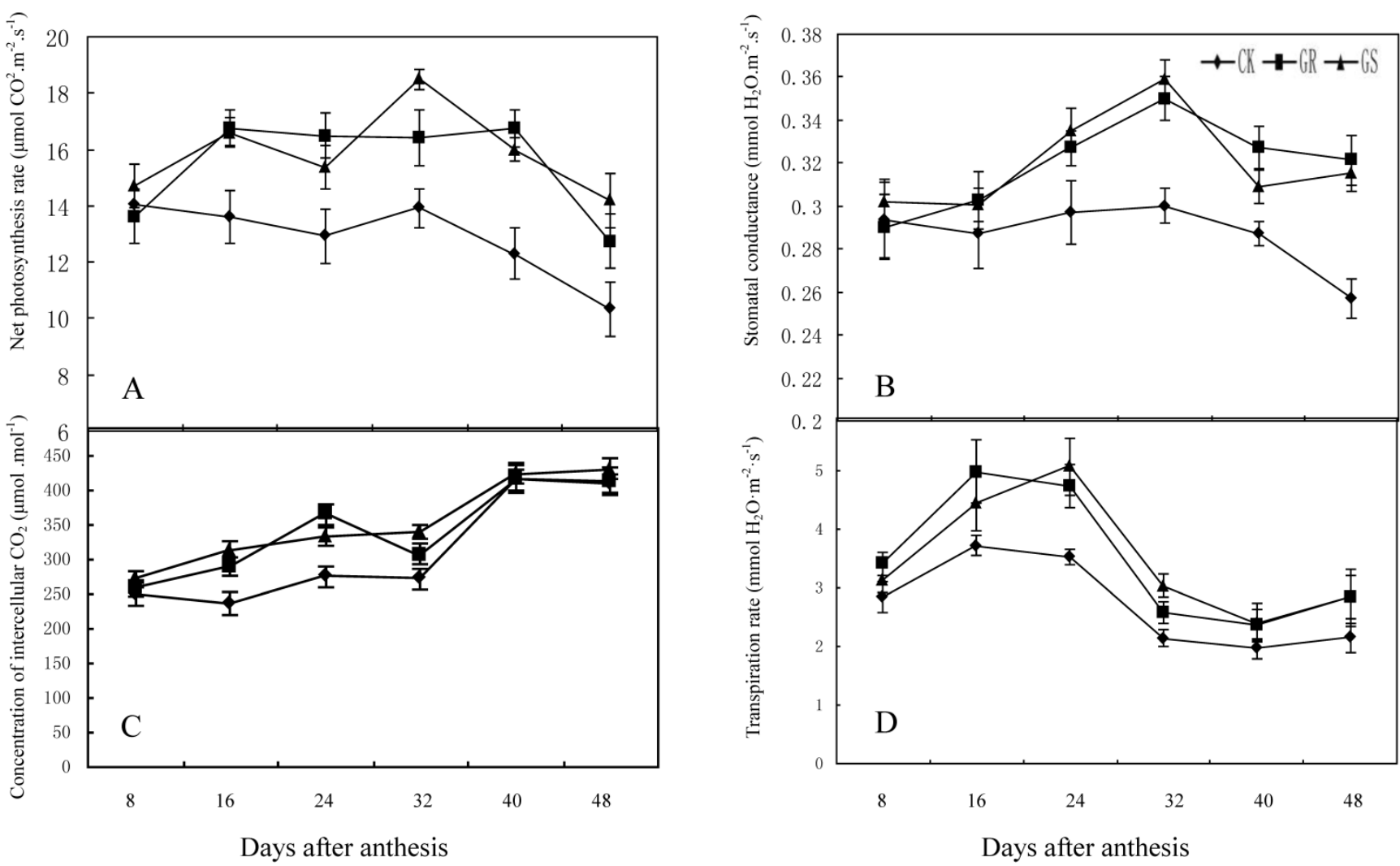

Fig. 2 Effect of grafting on net photosynthesis rate (A), stomatal conductance (B), concentration of intercellular $\mathrm{CO}_{2}(\mathrm{C})$ and transpiration rate $(D)$ in muskmelon leaves.

These results were similar to previous studies on grafted cucumber $[36,37]$. Grafting significantly enhanced net photosynthesis rates during 16-48 DAA, stomatal conductance during 24-48 DAA and concentration of intercellular $\mathrm{CO}_{2}$ or transpiration rate during 16 to 32 DAA (Fig. 2). These findings were similar to the results on grafted oriental melon, watermelon, and citrus [38-40]. Grafting can improve net photosynthesis rate and enhance assimilate accumulation and thus enhancing growth potential and dry matter accumulation in roots, stems, leaves and fruits. Grafting, which improves stomatal conductance and intercellular $\mathrm{CO}_{2}$ concentration, will strengthen the transfer capability of photosynthetic substrates and the supply capability of photosynthetic materials to ensure increased photosynthesis efficiency. Grafting on inter-specific rootstocks can boost transpiration rates in the leaves thus improving water and mineral nutrient absorption capacity in plants. Grafting can remarkably increase net photosynthetic rates in leaves of muskmelon, due to increased chlorophyll content and leaf area, similar to what has been observed in grafted cucumbers $[41,42]$. Further studies to deter- mine the detailed effects of grafting on photosynthesis in muskmelon leaves are still needed.

\section{Effect of grafting on carbohydrate contents in muskmelon leaves}

In many plant species, such as arabidopsis, tomato, soybean, maize, sugar beet or tobacco, assimilated $\mathrm{CO}_{2}$ is exported exclusively in the form of sucrose. However, in addition to sucrose, raffinose and stachyose are also used for long distance transport in Cucurbitaceae $[26,35]$. Carbohydrates from photosynthesis in leaves will generate a large amount of translocation carbohydrates such as stachyose, partial raffinose and sucrose from stachyose metabolism, and then they will be loaded into the phloem for long distance transport to every sink organ in plant [43]. Currently available studies have confirmed that for a plant with RFOs-dominant translocation, loading and transportation in its phloem should follow symplastic pathway [44, 45]. Among numerous hypotheses supportive for such a pathway, the 'polymer trap model' maintains that sucrose synthesized in mesophyll cells enters the intermediary cells (specialized CCs in minor veins) by diffusion through specialized, 
highly branched plasmodesmata. Inside the intermediary cells, sucrose and galactinol are used in the synthesis of RFOs. Since the diameter of those RFOs molecules is larger than the pore size of plasmodesmata between mesophyll cells and intermediate cells, carbohydrate backflow to the mesophyll cells may be prevented. However, the single branch plasmodesmata pore units between intermediate cells and sieve element can accommodate the passage of these carbohydrate molecules and their flow into the sieve elements [26, 44]. The present study showed that fructose, glucose and sucrose contents in functional leaves were $6.09 \mathrm{mg} \cdot \mathrm{g}^{-1}, 7.53 \mathrm{mg} \cdot \mathrm{g}^{-1}$ and $9.04 \mathrm{mg} \cdot \mathrm{g}^{-1}$ respectively, while the contents of galactinol, raffinose and stachyose were slightly low and $<1.25 \mathrm{mg} \cdot \mathrm{g}^{-1}$ in all treatments (Fig. 3). The lower content of galactinol may be due to its utilization during synthesis of sugars such as stachyose and raffinose. Meanwhile the lower content of raffinose and stachyose may be significantly related to a large amount of raffinose and stachyose loading and export after being synthesized. In addition, grafting reduces the fructose and glucose content in the leaves during the early and middle developmental stages while it accelerates the synthesis and accumulation in terms of sucrose, galactinol, raffinose and stachyose during middle and later developmental stages. Grafting on inter-specific rootstocks can reduce total carbohydrate accumulation during early development and increase starch accumulation in the later developmental stage of leaves. The changes in carbohydrate contents in leaves can be considered as comprehensive reflections of carbohydrate synthesis, metabolic transformation, loading and export in grafted muskmelon plants.

\section{Effect of grafting on carbohy- drate-metabolizing enzymes in muskmelon leaves}

We elucidated the response of enzymes involved in carbohydrate metabolism in muskmelon leaves grafted on inter-specific rootstocks to gain a better understanding on the effects of grafting on carbohydrate metabolism. There have been some reports on sucrose metabolism in leaves so far only $[29,46]$. The key enzymes in sucrose metabolism include sucrose synthase, sucrose phosphate synthase and invertase [47]. Of these, sucrose phosphate synthase is the enzyme necessary for sucrose synthesis, and invertase is involved in sucrose decomposition. Sucrose synthase, the third enzyme can not only catalyze sucrose synthesis, but can decompose sucrose as well [48]. The raffinose family oligosaccharides (RFOs) metabolism related enzymes mostly inculde galactinol synthase, raffinose synthase and stachyose synthase. Galactinol synthase is the enzyme in the first step of catalytic synthesis for the raffinose family oligosaccharides [49]. Raffinose synthase is a key enzyme in converting sucrose into raffinose [50]. And stachyose synthase, a kind of soluble enzyme existing in cytoplasm, will catalyze raffinose into stachyose [51]. Therefore, the activities of carbohydrate-metabolizing enzymes in leaves are crucially important to the carbohydrate synthesis, transportation and accumulation in muskmelon [52]. Photosynthetic carbon metabolism in muskmelon leaves is thought to be one of the important factors in soluble sugar synthesis, plant growth and fruit yield. However, there are few research reports about the influence of grafting on carbohydrate metabolism in muskmelon leaves. In the present study, grafting muskmelons on inter-specific rootstocks did not change the general trend of carbohydrate metabolism related enzyme activity in leaves during development (Fig. 5A-F). However, grafting muskmelon on inter-specific rootstock increased acid invertase and neutral invertase activities in leaves during the early and middle developmental stages with more pronounced effects on acid invertase than neutral invertase. However, grafting reduced fructose and glucose contents in leaves in the early and middle developmental stages. One explanation for this could possibly be because more glucose and fructose were being utilized for the leaf growth in GR's or GS's (Fig. 3A-B). Grafting increased sucrose synthase activity in the later developmental stage compared to CK (Fig. 5C). Sucrose phosphate synthase and stachyose synthase activity were higher during the middle and later developmental stages in grafted muskmelon leaves compared to CK (Fig. 5D-E). Grafting had slight influence on alkaline a-galactosidase activity (Fig. 5F), a fact favorable for stachyose production in muskmelon leaves (Fig. 3F). During 8 to 40 DAA increased stchyose levels was noted in GS whereas, a similar increase in stachyose levels was only observed on 32 DAA for GR. This indicates that the carbohydrate loading and export levels of GR are higher than those of GS. Experiments are underway to determine if the carbohydrates loading and export capability for GS and GR are remarkably higher than that of CK.

The accumulation and export of photosynthates in leaves is another major influential element on photosynthesis [53]. Our results indicate that the grafted muskmelon leaves generate and accumulate more translocating sugars such as sucrose, raffinose and stachyose than the ungrafted (CK). Though the carbohydrate supply capacity was greater in grafted muskmelons, it did not exert a feedback inhibition on photosynthesis. This could most likely be due to appropriate photoassimilates contents in leaves. Thus it 
should follow the hypothesis of inhibition threshold of photosynthetic product $[54,55]$. This hypothesis suggests that though there is photoassimilates feedback inhibition in plants, such an inhibition may only exist when photoassimilates accumulate to very high level. Under stress free conditions, carbohydrates contents in leaves for many plants do not exceed their inhibition threshold of photosynthetic product $[54,56$, 57]. Grafting increased the translocating sugars con-

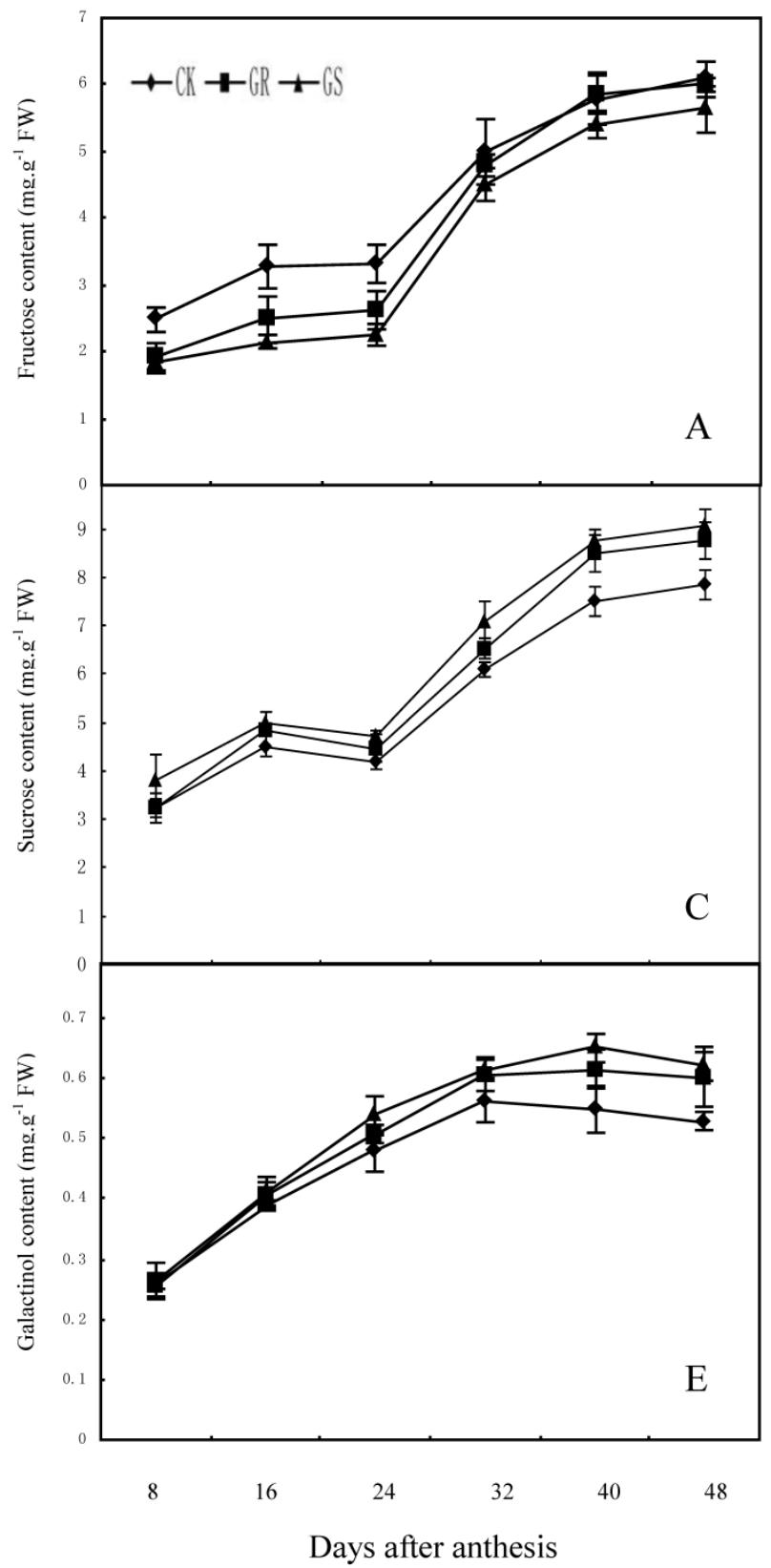

tent in muskmelon leaves and at the same time also improved photosynthetic capacity in grafted plants without exceeding the inhibition threshold.

In conclusion the increase in photosynthesis and carbohydrate metabolism due to grafting has the potential to improve fruit quality and yield in muskmelon. Breeding and developing appropriate rootstock and scion combinations can significantly help improve fruit quality and yield.

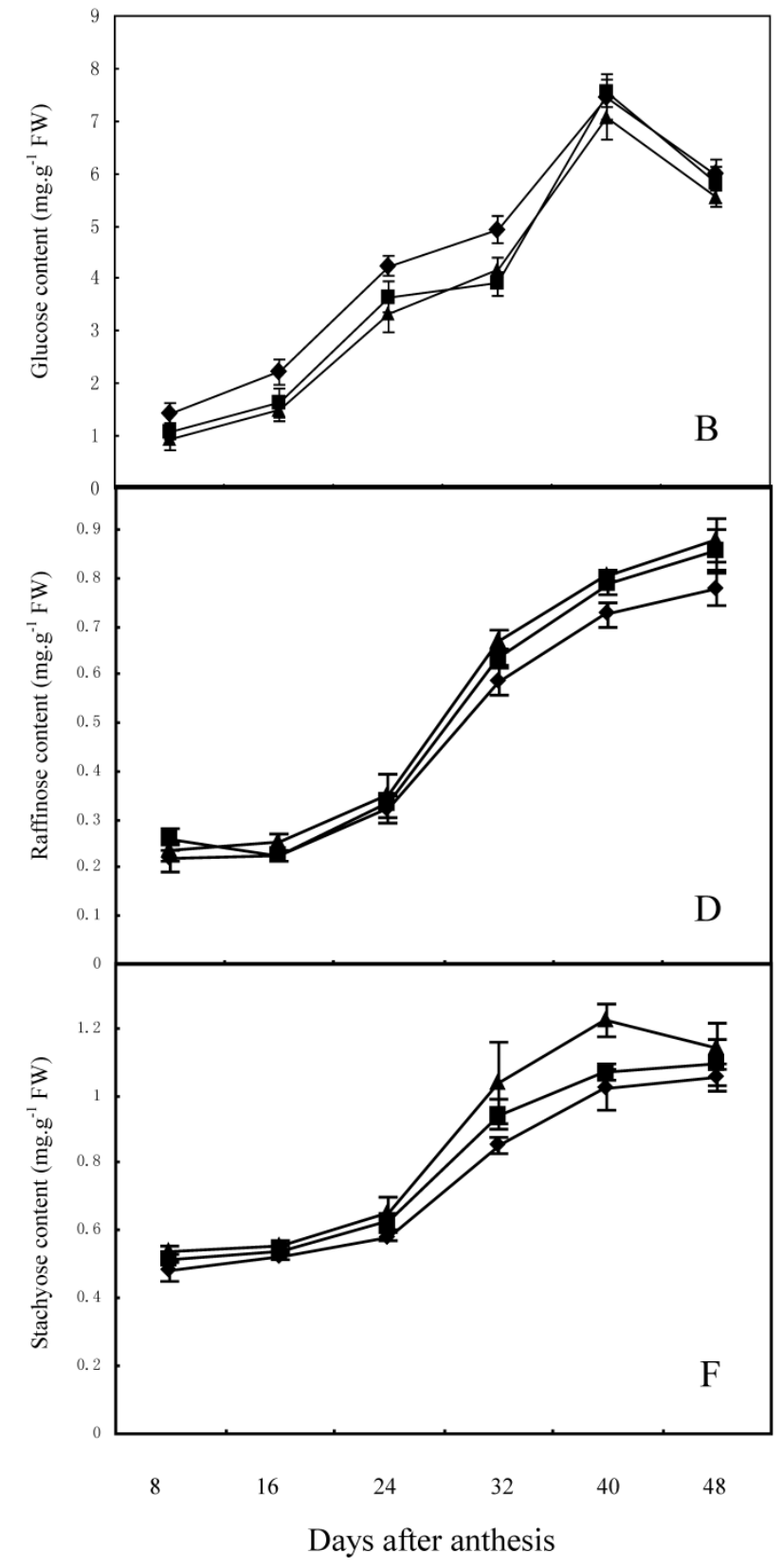

Fig. 3 Effect of grafting on fructose (A), glucose (B), sucrose (C), raffinose (D), galactinol $(E)$ and stachyose $(F)$ contents in muskmelon leaves. 

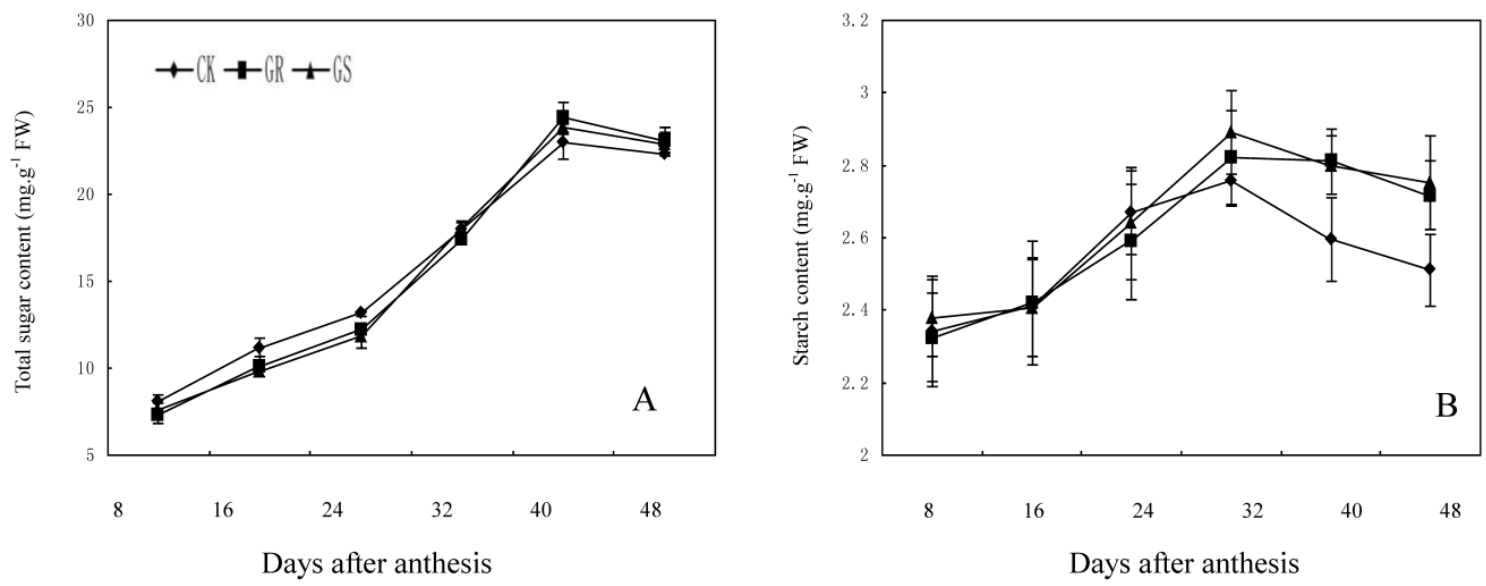

Fig. 4 Effect of grafting on total sugar (A) and starch contents (B) in muskmelon leaves.
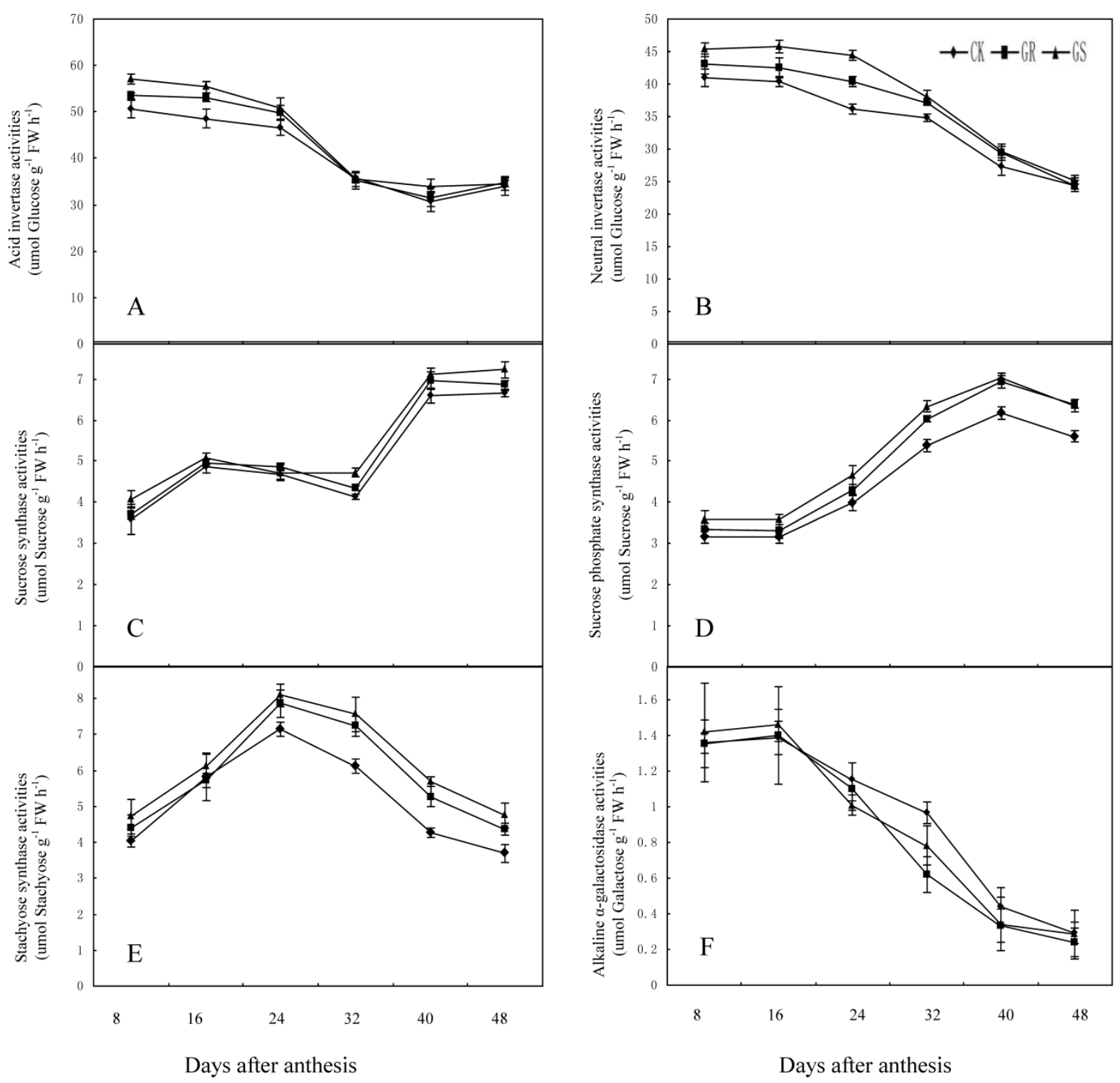

Fig. 5 Effect of grafting on acid invertase (A), neutral invertase (B), sucrose synthase (C), sucrose phosphate synthase (D), stachyose synthase $(E)$ and alkaline $\alpha$-galactosidase $(F)$ activities in muskmelon leaves. 


\section{Acknowledgments}

The studies were funded by National Science Support Item, China (2006BAD07B04), National Natural Science Foundation of China (30972000), Major Scientific and Technological Project of Liaoning Province, China (2006215001) and Natural Science Fund of Liaoning Province, China (20062112). We also wish to acknowledge Mr. Huaisong Wang of the Chinese Academy of Agricultural Sciences (CAAS) for kindly providing the scion cultivar worked with.

\section{Conflict of Interests}

The authors have declared that no conflict of interest exists.

\section{References}

1. Cheng ZJ, Wang HS, Zhang ZB, et al. Genetic diversity of melon (Cucumis melo L.) germplasm based on AFLPs. Acta Bot Boreali-Occidentalia Sinica. 2007; 27:244-248

2. Keiko O, Akio U, Tomoko T, et al. Enrichment of sugar content in melon fruits by hydrogen peroxide treatment. J Plant Physiol. 2009; 166:569-578

3. Song WY, Zhang ZB, Shao HB, et al. Relationship between calcium decoding elements and plant abiotic-stress resistance. Int J Biol Sci. 2008; 4: 116-125

4. Liu YF, Li TL, Qi HY, et al. Effects of grafting on carbohydrate accumulation and sugar-metabolic enzyme activities in muskmelon. Afr J Biotechnol. 2010; 9:25-35

5. Lee JM, Oda M. Grafting of herbaceous vegetable and ornamental crops. Hort Rev. 2003; 28:61-124

6. Pavlou G.C, Vakalonnakis DJ, Ligoxigakis EK. Control of root and stem rot of cucumber, caused by F. oxysporum f. sp radicis cucumerinum, by grafting onto resistant rootstocks. Plant Dis. 2002; 86: 379-382

7. Shao HB, Chu LY, Lu ZH, et al. Primary antioxidant free radical scavenging and redox signaling pathways in higher plant cells. Int J Biol Sci. 2008; 4: 8-14

8. Angela RD, Penelope PV, Richard H, et al. Grafting effects on vegetable quality. HortScience. 2008; 43: 1670-1672

9. Lee JM. Cultivation of grafted vegetables I: Current status, grafting methods and benefits. HortScienc. 1994; 29:235-239

10. Zhang JM, Ge ZD. Effects of grafting application on muskmelon. Chin Cucurbit Veg. 2002; 1:26-27

11. Ristaino JB, Thomas W. Agriculture, methyl bromide and the ozone hole, can we fill the gap? Plant Dis. 1997; 81: 964-977

12. Angela RD, Penelope PV, Sakata $Y$, et al. Cucurbit grafting. Crit Rev Plant Sci. 2008; 27: 50-74

13. Jiao ZG, Wang CQ, Dong YM, et al. Effects of grafting on development and quality of cucumber. Shandong Agri Sci. 2000; 1: $26-30$

14. Li TL, Liu YF, Qi HY, et al. Grafting effects on root activity and amino acid contents in bleeding sap of muskmelon. Hort Environ Biotechnol. 2009; 50: 1-6

15. Liu HY, Zhu ZJ, Diao M, et al. Characteristic of the sugar metablolism in leaves and fruits of grafted watermelon during fruit development. Plant Physiol Commun. 2006; 42: 835-840

16. Xu CQ, Li TL, Qi HY. Effects of grafting on development, carbohydrate content and sucrose metabolizing enzymes activities of muskmelon fruit. Acta Hort Sinica. 2006; 33: 773-778

17. Yu XY, Wang XF, Fan JD, et al. Cloning and characterization of a sucrose phosphate synthase-encoding gene from muskmelon. J Amer Soc Hort Sci. 2007; 132: 557-562
18. Yu XY, Wang $X F$, Zhang WQ, et al. Antisense suppression of an acid invertase gene (MAI1) in muskmelon alters plant growth and fruit development. J exper bot. 2008; 59: 2969-2977

19. Greutert H, Keller F. Further evidence for stachyose and sucrose $/ \mathrm{H}^{+}$antiporters on the tonoplast of Japanese artichoke (Stachys sieboldii) tubers. Plant Physiol. 1993; 101: 1317-1322

20. Madore MA. Carbohydrate metabolism in photosynthetic and nonphotosynthetic tissues of variegated leaves of coleus blumei Benth. Plant Physiol. 1990; 93: 617-622

21. Robbins NS, Pharr DM. Regulation of photosynthetic carbon metabolism in cucumber by light intensity and photosynthetic period. Plant Physiol. 1987; 85: 592-597

22. Andreas B, Peterbauer T, Richter A. Inhibition of raffinose oligosaccharide breakdown delays germination of pea seeds. J Plant Physiol. 2007; 164: 1093-1096

23. Henrissat B, Coutinho PM, Davies GJ. A census of carbohydrateactive enzymes in the genome of Arabidopsis thaliana. Plant Mol Biol. 2001; 47: 55-72

24. Micallef BJ, Haskins KA, Vanderveer PJ. Altered photosynthesis, flowering and fruiting in transgenic tomato plants that have incnthesis. Planta. 1995; 196: 327-334

25. Salerno G.L, Curatti L. Origin of sucrose metabolism in higher plants: when, how and why? Trends Plant Sci. 2003; 8: 63-69

26. Brain GA, Keller F, Robert T. Symplastic continuity between companion cells and the translocation stream: Long-distance transport is controlled by retention and retrieval mechanisms in the phloem. Plant Physiol. 2003; 131: 1518-1528

27. Pharr DM, Steven $\mathrm{CH}$, Harriet NS. Leaf carbohydrate status and enzymes of translocate synthesis in fruiting and vegetative plants of Cucumis sativus L. Plant Physiol. 1985; 77: 104-108

28. Porra RJ, Thompson WA, Kriedemann PE. Determination of accurate extinction coefficients and simultaneous equations for assaying chlorophylls $a$ and $b$ extracted with four different solvents: verification of the concentration of chlorophyll standards by atomic absorption spectroscopy. Biochim Biophys Acta. 1989; 975: 384-394

29. Pinheiro C, Rodrigues AP, Chaves MM. Sugar metabolism in developing lupin seeds is affected by a short-term water deficit. J Exp Bot. 2005; 56: 2705-2712

30. Wardlaw IF, Willenbrink J. Carbohydrate storage and mobilisation by the culm of wheat between heading and grain maturity: the relation to sucrose synthase and sucrose-phosphate synthase. Austra J Plant Physiol. 1994; 21: 255-271

31. Monika ES, James DB, John DW, et al. Galactosyl-sucrose metabolism and UDP-galactose pyrophosphorylase from Cucumis melo L. fruit. Physiol Plant. 1999; 106: 9-16

32. Peterbauer T, Richter A. Galactosylononitol and stachyose synthesis in seeds of adzuki bean: purification and characterization of stachyose synthase. Plant Physiol. 1998; 117: 165-172

33. Ho LC, Shaw AF, Hammond JB, et al. Source-sink relationships and carbon metabolism in tomato leaves ${ }^{14} \mathrm{C}$ assimilate compartmentation. Ann Bot. 1983; 52: 365-372

34. Handley LW, Pharr DM, McFeeters RF. Carbohydrate changes during maturation of cucumber fruit. Plant Physiol. 1983; 72: 498-502

35. Mitchell DE, Michelle VG, Monica AM. Patterns of assimilate production and translocation in muskmelon (Cucumis melo L.). Plant Physiol. 1992; 99: 959-965

36. Sun $\mathrm{Y}$, Huang $\mathrm{W}$, Tian $\mathrm{XH}$, et al. Study on growth situation, photosynthetic characteristics and nutrient absorption characteristics of grafted cucumber seedlings. Plant Nutr Fert Sci. 2002; 8: 181-185

37. Zhang HM, Xie J, Yu JZ, et al. The growth, photosynthesis and fruit quality of different type cucumber varieties grafted on to pumpkin seedlings. Acta Agr Shanghai. 2008; 24: 40-43 
38. Qi HY, Li TL, Liu YF, et al. Effects of grafting on photosynthesis characteristics, yield and sugar content in melon. J Shenyang Agr Univ. 2006; 37: 155-158

39. Zhu ZJ, Liu HY, Shi QH. Effects of low temperature stress on characteristics of photosynthesis in leaves of own-rooted and grafted watermelon seedling. Adv Hort. 2004; 6: 434-440

40. Carmen MG, Liosa MJ, Antonio Q, et al. Rootstock effects on leaf photosynthesis in 'Navelina' trees grown in calcareous soil. HortScience. 2009; 44: 280-283

41. Li YJ, Liang GY, Liu XJ, et al. Proteomic study on grafted and non-grafted cucumber (Cucumis sativus L.). Acta Hort Sinica. 2009; 36: 1147-1152

42. Omid A, Keilin T, Glass A, et al. Characterization of phloem sap transcription profile in melon plants. J Exp Bot. 2007; 58: 3645-3656

43. Hu LP, Meng FZ, Wang SH, et al. Changes in carbohydrate levels and their metabolic enzymes in leaves, phloem sap and mesocarp during cucumber (Cucumis sativus L.) fruit development. Scientia Hort. 2009; 121: 131-137

44. Robert T. Phloem loading and plasmodesmata. Trends Plant Sci. 1996; 1: 418-423

45. McCaskill A, Robert T. Phloem loading in Verbascum phoeniceum L. depends on the synthesis of raffinose family oligosaccharides. Proc Natl Acad Sci USA. 2007; 104: 19619-19624

46. Gao Zf, Marina P, Eli Z, et al. Carbohydrate metabolism during early fruit development of sweet melon (Cucumis melo). Physiol Plant. 1999; 106: 1-8

47. Qi HY, Li TL, Liu HT, et al. Studies on carbohydrate content and sucrose metabolizing enzymes activities in different parts of tomato. Acta Hort Sinica. 2005; 32: 239-243

48. Zhao ZZ, Zhang SL, Xu CJ, et al. Roles of sucrose metabolizing enzymes in accumulation of sugars in satsuma mandarin fruit. Acta Hort Sinica. 2001; 28: 112-118

49. Saravitz DM, Pharr DM, Carter TE. Galactinol synthase activity and soluble sugars in developing seeds of four soybean genotypes. Plant Physiol. 1987; 83: 185-189

50. Peterbauer T, Mucha J, Mach L, et al. Chain elongation of raffinose in pea seeds-isolation, characterization, and molecular cloning of a multifunctional enzyme catalyzing the synthesis of stachyose and verbascose. J Biol Chem. 2002; 277: 194-200

51. Holthaus U, Schmitz K. Distribution and immunolocalization of stachyose synthase in Cucumis melo L. Planta. 1991; 185: 479-486

52. Emilie AR, Robert T. A comprehensive picture of phloem loading strategies. Proc Natl Acad Sci USA. 2009; 106: 14162-14167

53. Christine AR. The calvin cycle revised. Photosyn Res. 2003; 75: $1-10$

54 Proietti P. Effect of fruiting on leaf gas exchange in olive (Olea europaea L.). Photosyn. 2000; 38: 397-402

55. Xu DQ. The relationship between the photosynthate level and the photosynthetic rate. Plant Physiol Commun. 1986; 6: 1-8

56. Gucci R, Grappadelli LC, Tustin S, et al. The effect of defruiting at different stages of fruit development on leaf photosynthesis of "Golden Delicious" apple. Tree Physiol. 1995; 15: 35-40

57. Sharkey TD. Photosynthesis in intact leaves of $C_{3}$ plants: physics, physiology and rate limitations. Bot Rev. 1985; 51: 53-105 